EPJ Web of Conferences 92,02109 (2015)

DOI: $10.1051 /$ epjconf/ 20159202109

(C) Owned by the authors, published by EDP Sciences, 2015

\title{
Water distribution characteristics of spray nozzles in a cooling tower
}

\author{
Pavol Vitkovic ${ }^{1, \text { a }}$ \\ ${ }^{I}$ CTU in Prague, Department of Fluid Dynamics and Thermodynamics, 16607 Prague, Czech Republic
}

\begin{abstract}
Water distribution characteristics of spray nozzles with spray plates used to distribute cooling water to the cooling fills in a cooling tower is one of the important parameters for the selection of nozzles. Water distribution characteristic describes the distribution of water from the axis of the nozzle along a fill. One of the parameters affecting the water distribution characteristic of the nozzle is airflow velocity of counter flow airstream. Water distribution characteristics are commonly measured using by a set of containers. The problem with this method of the measurement of characteristics is block of the airflow with collections of containers. Therefore, this work is using the visualization method.
\end{abstract}

\section{Introduction}

Spray nozzles with plate are used to distribute water in wet cooling towers. Cooling towers are evaporative heat rejection devices, which take out the waste heat to the atmosphere through the cooling of water by the air. The cooling tower (Figure 1.) is basically a mixed heat exchanger.

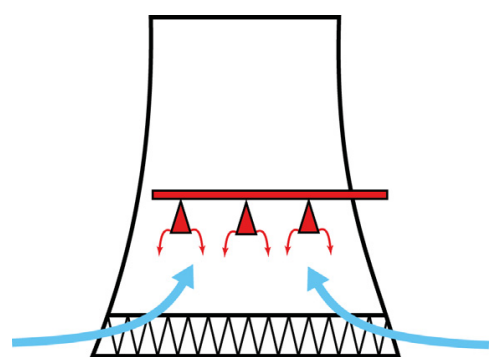

Figure 1. A wet cooling tower as a mixed heat exchanger consist of spray zone, fill zone and rain zone

Water distribution systems in the cooling tower are consisting of pipelines and nozzles. First nozzles with plate used in cooling tower are made from ceramics or glass usually (Figure 2.). The nozzle consist of two separate parts a spray nozzle and a spray plate. The spray nozzle is inserted into the water distribution channel. The spray plate is mounted to the wood rod bellow the nozzle.

From ceramics or glass nozzles with separate plate we obtain compact nozzles with spray plate made from plastic (Figure 3.) used at present. The spray nozzle has two important characteristics used in cooling tower design. The first one is a flow rate characteristic. This characteristic is usually curve in the graph. Each curve represent data for different orifice diameter of a nozzle. The $\mathrm{x}$-axis indicates flow rate of water and the y-axis

a Corresponding author: pavol.vitkovic@fs.cvut.cz shows a head of water. The second characteristic is a water distribution characteristic. It is the water distribution below the single spray nozzle. This characteristic is described for a fill inlet level usually. This characteristic is a curve in the graph also. The $\mathrm{x}$-axis shows a distance from nozzle axis and the $\mathrm{y}$-axis indicates the water flow rate. Water distribution system usually consists of measuring cups arranged in a line [1] or grid of array of measuring cylinders [2]. The methods for collecting water to the measuring cylinders are provided by the water distribution characteristic with no effect of airstream usually and just for one distance between a nozzle and a fill.

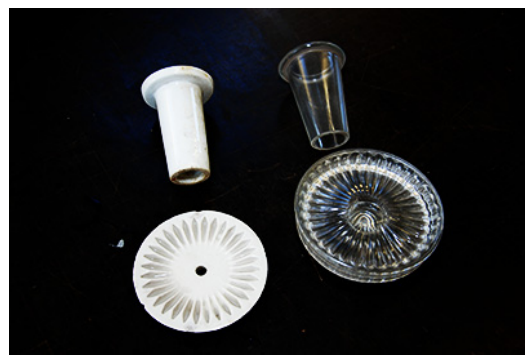

Figure 2. Nozzles with plate made from a ceramics and a glass

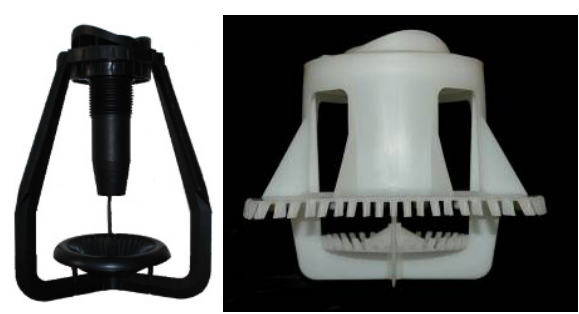

Figure 3. The spray nozzles RT240 and FANS made from plastic 
Those two nozzles (Figure 3.) are used in the experiment.

In this work visualisation method of liquid particles is used. This method is used in study of liquid jet in crossflow [3], [4], [5], [6]. In this case the light source illuminates all volume filled by liquid jet. Light sheet is used to create specific control volume. And it does not consist just of water structure generated by the spray nozzle with plate.

\section{Experimental facility and method}

Experimental facility shown in Figure 3., consists of the mechanical draft wet cooling tower with the test cell, the water channel and the water basin with hot water. The test cells are placed in the spray nozzle with plate and the film fill. Cross section of the test cell is $1520 \times 820 \mathrm{~mm}$. Water from test cell is collected in the water channel bellow the test cell. The wet cooling tower has a centrifugal fan with variable speed at outlet. The pipeline with the nozzle has inside diameter $100 \mathrm{~mm}$. Distance between pipelines and the film fill is $500 \mathrm{~mm}$.

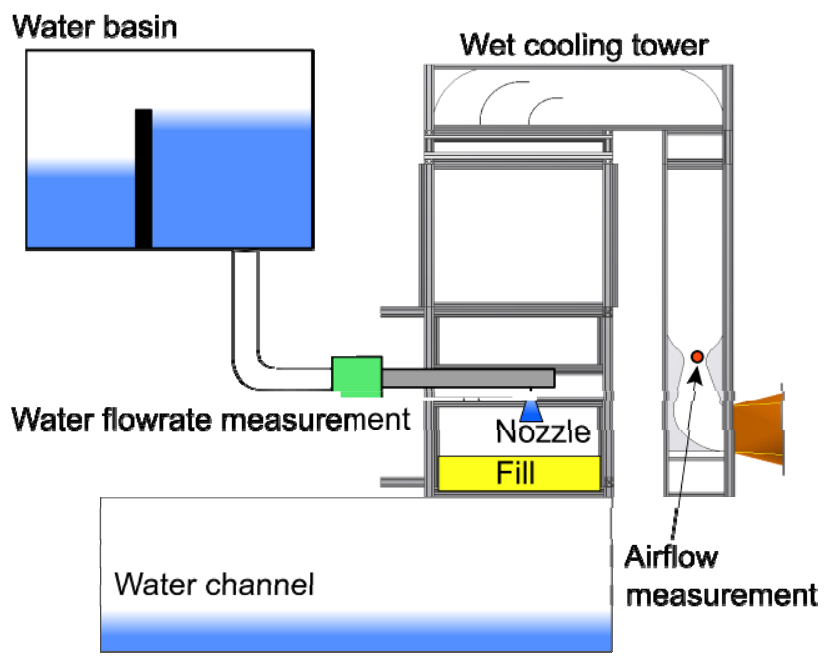

Figure 3. Experimental facility

Visualisation method for the measurement of water distribution characteristics of the spray nozzles was used. The measurement equipment consists of a camera and a LED array $(80 \mathrm{~W})$ for a light sheet generation as shown in Figure 4. The spray nozzle generates water drops. The water drops are falling past the test section. A light sheet sets up a control volume in the test cell. Each water drop is illuminated by light sheet during the passing this control volume.

Between the camera (Nikon D80) and the light sheet was a water film on plexiglass windscreen. The water film blocked contact between water droplets and plexiglass windscreen. The water functioned like a natural median filter.

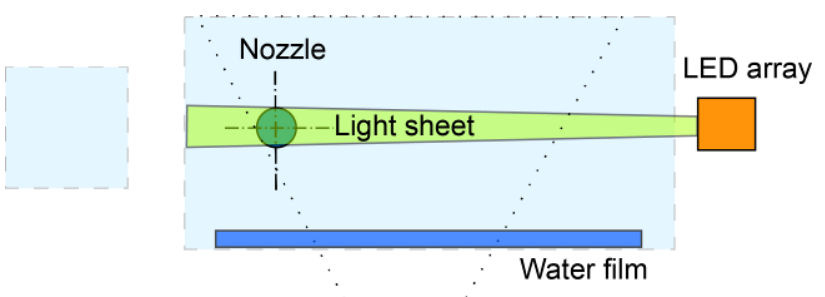

Camera

Figure 4. Experiment setup - visualisation

\section{Experimental results}

During the measurement there were obtained set of images with long exposition. Each image represents a water distribution around the nozzle in the control volume. The images contains the information about water distribution characteristic of the nozzle. Each horizontal line of an image is the water distribution characteristic in grayscale units. The grayscale intensity on the images corresponding with water flow rate in each point of an image. The grayscale intensity of the image is dimensionless water flow rate. A plot of grayscale intensity of one horizontal line of the image is water distribution characteristics of the spray nozzle with plate. The $\mathrm{x}$-axis shows a distance from nozzle axis and the $\mathrm{y}$ axis indicate dimensionless water flow rate from grayscale intensity. Each horizontal line is distance between the nozzles and the hypothetic enter in to the fill.

One image was taken with condition of one value of water flow and one value of air velocity. Each measurement had following parameters of water flow: $0.71 / \mathrm{s}, \quad 0.71 / \mathrm{s}, \quad 0.91 / \mathrm{s}, 1.01 / \mathrm{s}, 1.11 / \mathrm{s}$ and air velocity: $0 \mathrm{~m} / \mathrm{s}, 1 \mathrm{~m} / \mathrm{s}, 2 \mathrm{~m} / \mathrm{s}, 3 \mathrm{~m} / \mathrm{s}, 4 \mathrm{~m} / \mathrm{s}$.

\subsection{Nozzle RT240}

Figure 5 presents data from the visualisation of water distribution of the nozzle RT240. The Figure is divided to 20 frames. Each frame represents the visualisation of water distribution of the nozzle for specific water flow rate and air flow rate. First frame at left upper coroner of figure is for $0.71 / \mathrm{s}$ water flow rate and $0 \mathrm{~m} / \mathrm{s}$ air velocity.

Row indicates increasing air flow rate and columns shows changing the water flow rate.

Set of frames (Figure 5.) showing the moving high intensity peak. Near spray plate (Figure 6.) can occure with the water film. This peak is formed by the water structure created by the water film near the plate. This water film is very sensitive to the air velocity. If the air velocity incises them the water film move up.

The visualisation is created with the spray plate splatted in half for better observation at Figure 6 . The plexiglass wall is replaced with the missing part of spray plate. Water flow rate is $0.85 \mathrm{l} / \mathrm{s}$ without forced airstream. 


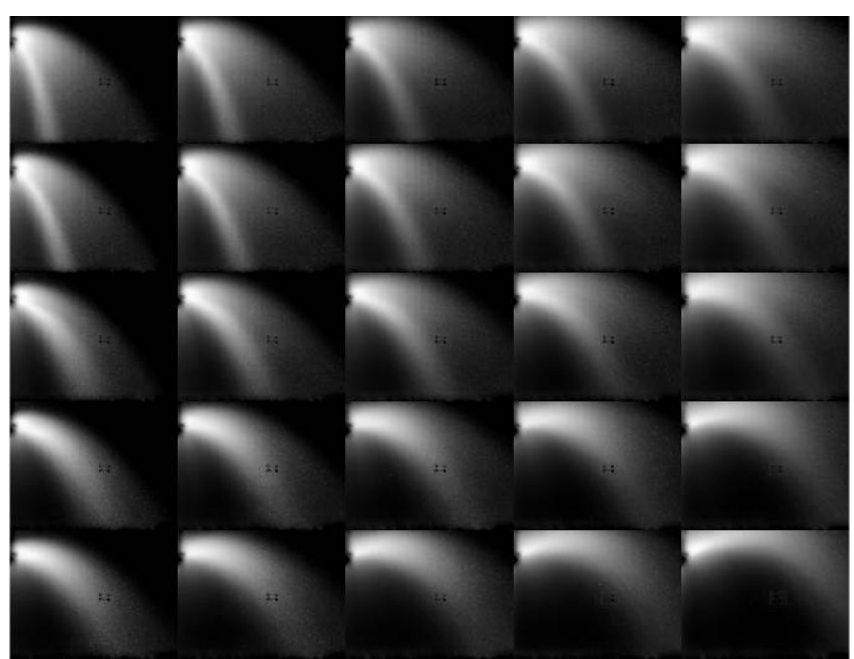

Figure 5. The visualisation of the water distribution of the nozzle RT240.

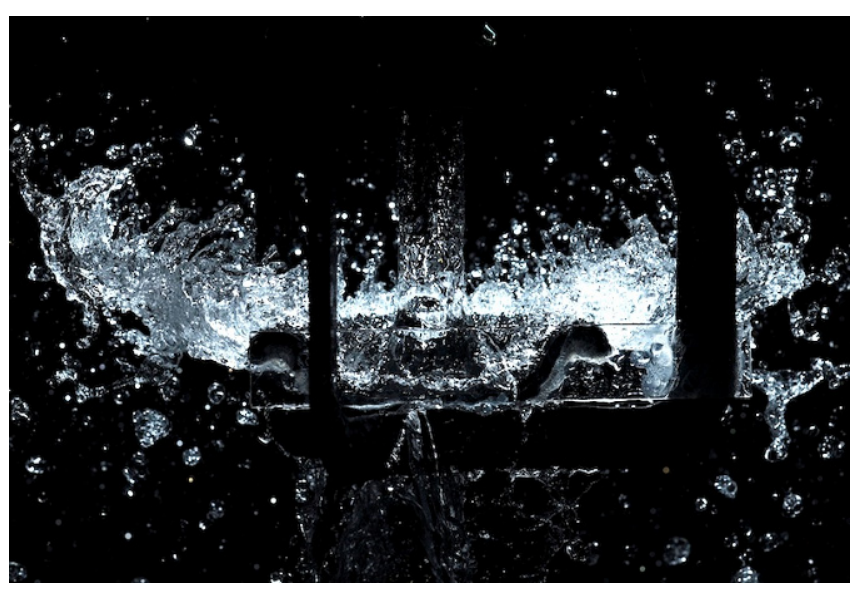

Figure 6. The water film near the spray plate of the nozzle RT240.

The following figure shows the water distribution of the nozzle RT240 at distance about $400 \mathrm{~mm}$ from the pipeline (Figure 7.). It is about $95 \mathrm{~mm}$ above the film fill.

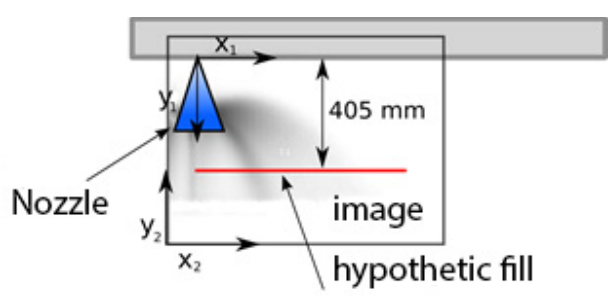

Figure 7. Distance between the hypothetic fill and the pipeline.

The high peak is very easy to identify on the graph. The peak is a move from the axis to the maximum operate radius of the nozzle. This is the effect of counterflow. This effect radically changes the water distribution characteristics of the nozzle.

The maximum operating radius of the nozzle is about $600 \mathrm{~mm}$ for the water flow rate 0.7 and $0.8 \mathrm{l} / \mathrm{s}$ and about $800 \mathrm{~mm}$ for the water flow rate $0.9,1$ and $1.1 \mathrm{1} / \mathrm{s}$.
The maximum operating radius of the spray nozzle is more dependent on the water flow rate rather like the air velocity.

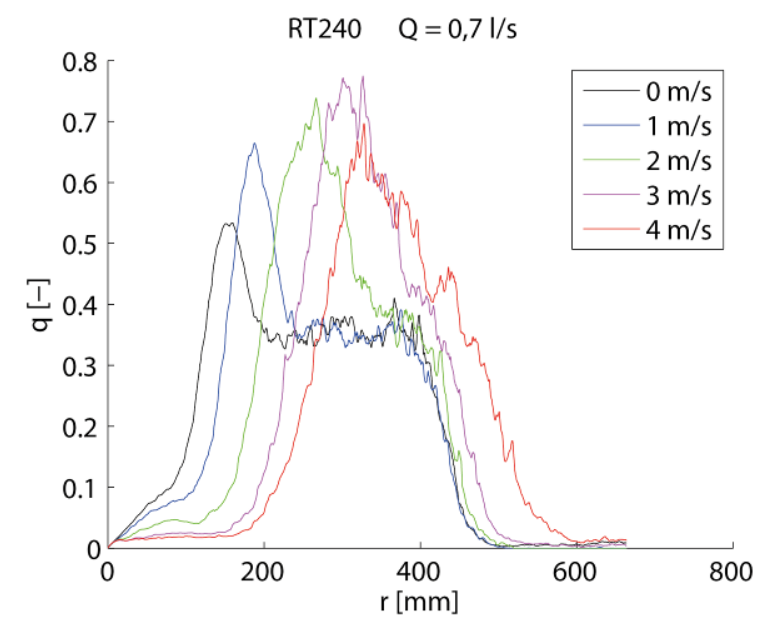

Figure 8. The water distribution of the nozzle RT240 for several velocities of crossflow airstream and same water flow rate $0.71 / \mathrm{s}$.

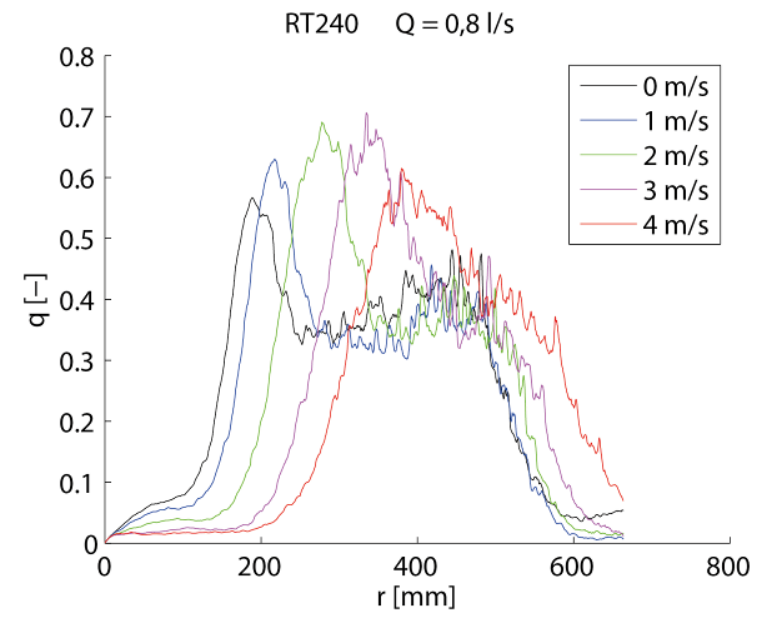

Figure 9. The water distribution of the nozzle RT240 for several velocities of crossflow airstream and same water flow rate $0.8 \mathrm{l} / \mathrm{s}$.

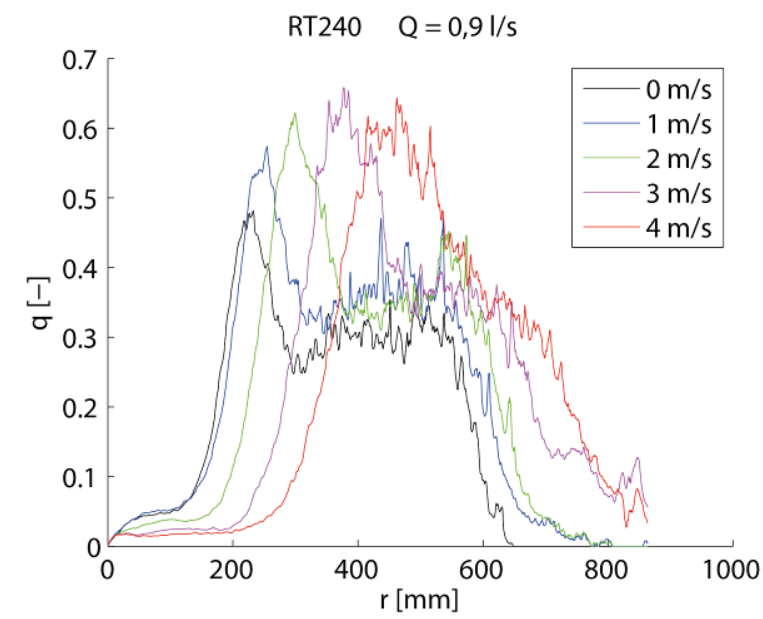

Figure 10. The water distribution of the nozzle RT240 for several velocities of crossflow airstream and same water flow rate $0.9 \mathrm{l} / \mathrm{s}$. 


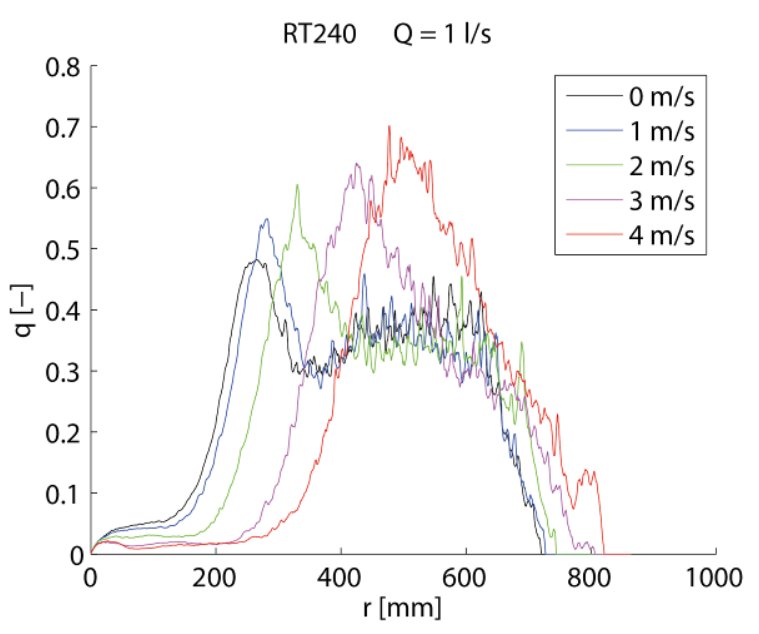

Figure 11. The water distribution of the nozzle RT240 for several velocities of crossflow airstream and same water flow

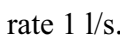

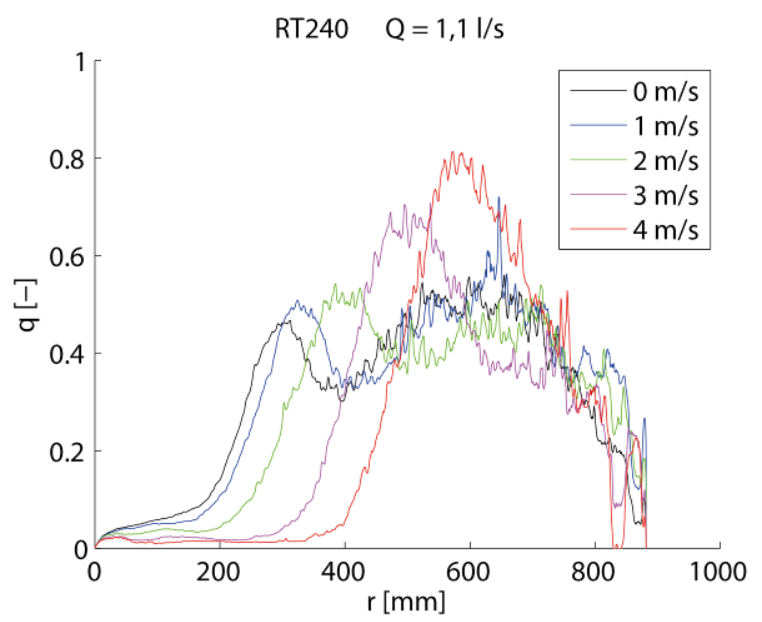

Figure 12. The water distribution of the nozzle RT240 for several velocities of crossflow airstream and same water flow rate $1.1 \mathrm{l} / \mathrm{s}$

\subsection{Nozzle FANS}

The nozzle FANS created water structure called water bell [7]. The water bell at Figure 14. is not closed. Shape of the water bell is changing with air velocity. The water bell is destroyed during the critical air velocity and then the water bell becomes to stream of the water droplets (Figure 15.).

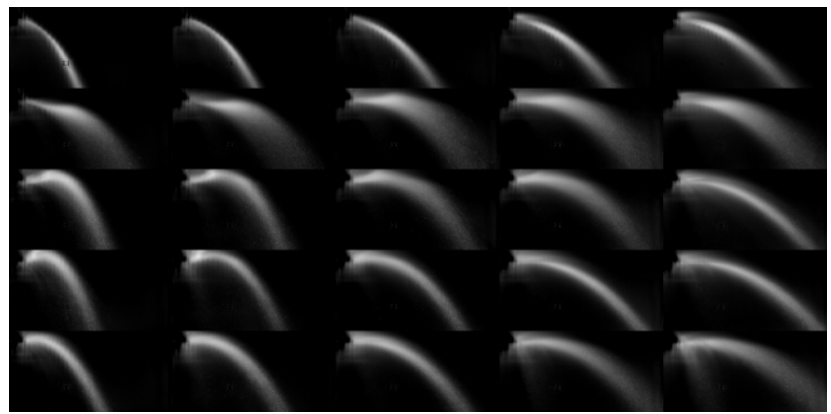

Figure 13. Visualisation of water distribution of the nozzle FANS.

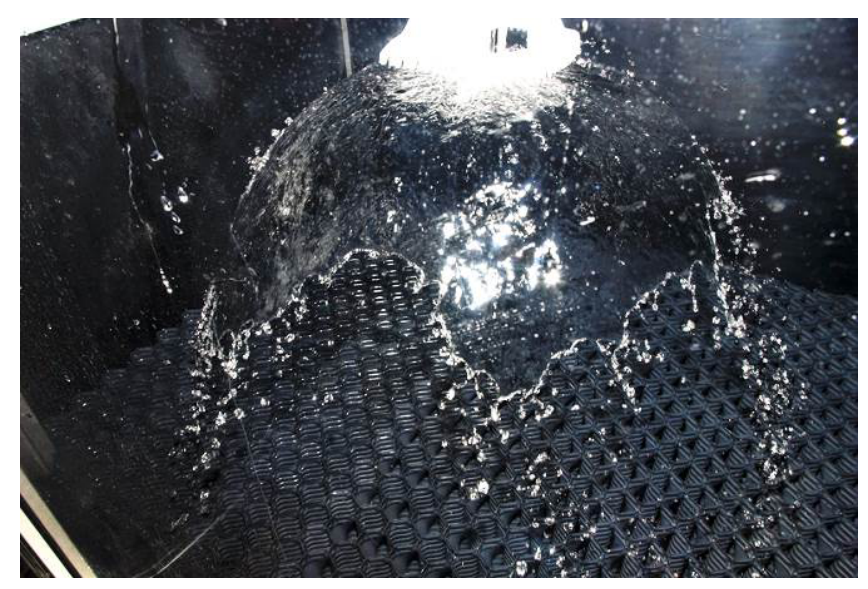

Figure 14. The nozzle FANS with water bell at low crossflow air velocity.

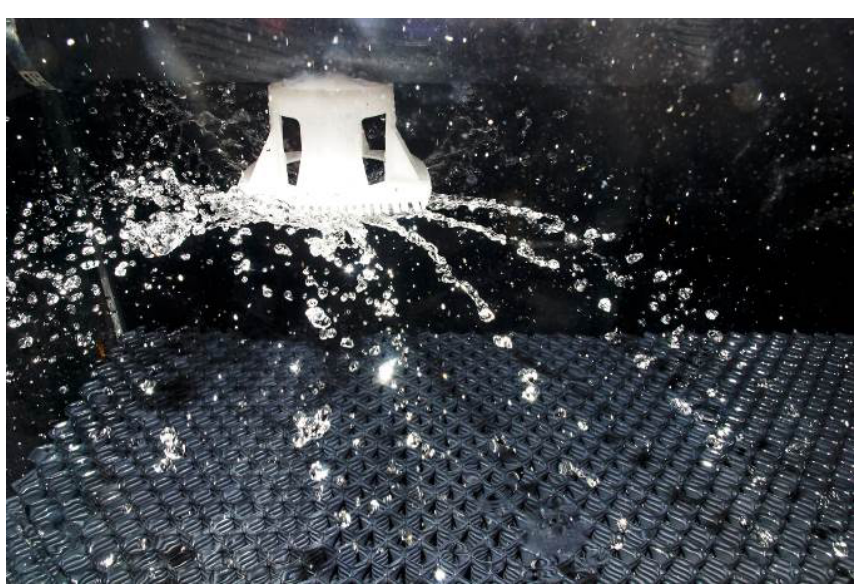

Figure 15. Water distribution of the nozzle FANS at high crossflow air velocity.

The water distribution characteristic of the nozzle FANS consist very high clear peak at $0 \mathrm{~m} / \mathrm{s}$ air velocity. This peak is created by water bell structure.

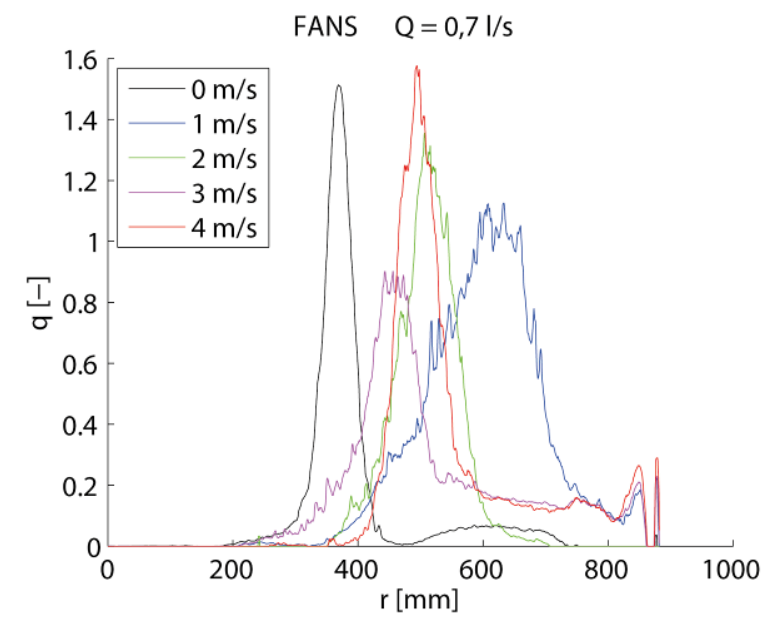

Figure 16. The water distribution of the nozzle FANS for several velocities of crossflow airstream and same water flow rate $0.7 \mathrm{l} / \mathrm{s}$. 
FANS $Q=0,8 \mathrm{l} / \mathrm{s}$

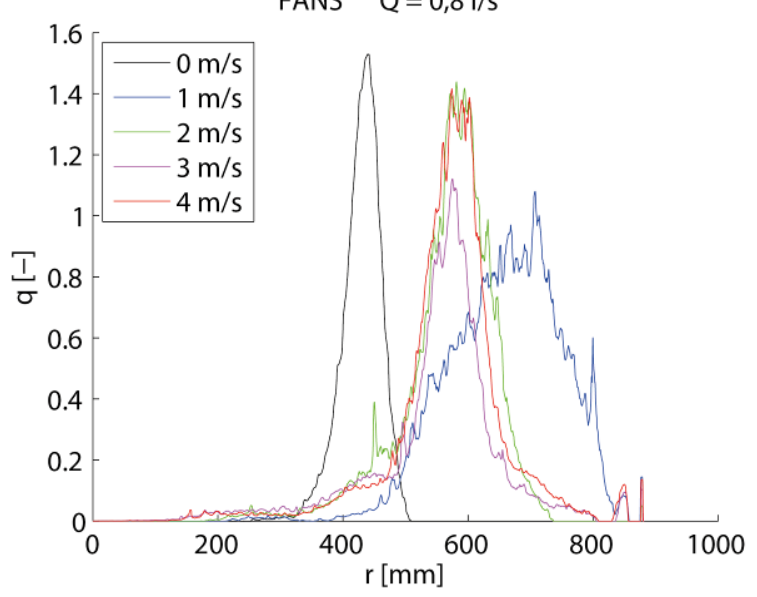

Figure 17. The water distribution of the nozzle FANS for several velocities of crossflow airstream and same water flow rate $0.8 \mathrm{l} / \mathrm{s}$

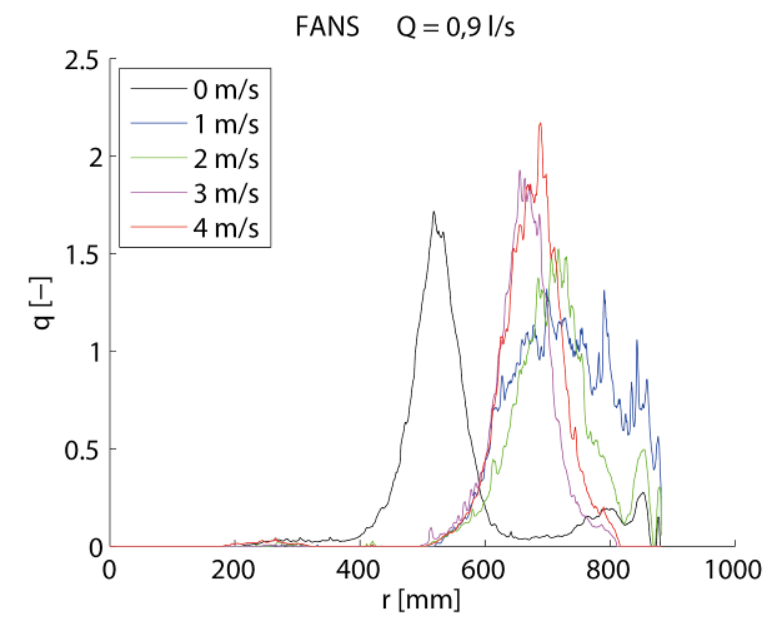

Figure 18. The water distribution of the nozzle FANS for several velocities of crossflow airstream and same water flow rate $0.9 \mathrm{l} / \mathrm{s}$.

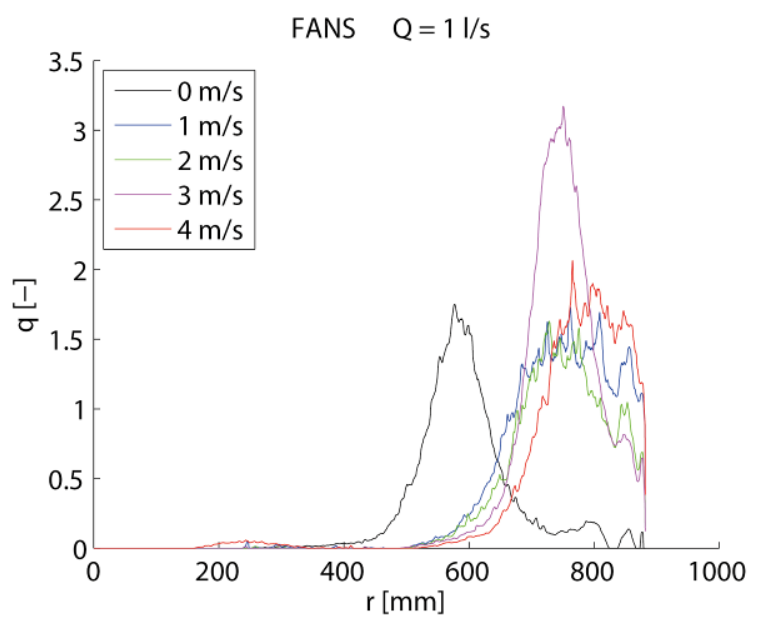

Figure 19. The water distribution of the nozzle FANS for several velocities of crossflow airstream and same water flow rate $11 / \mathrm{s}$

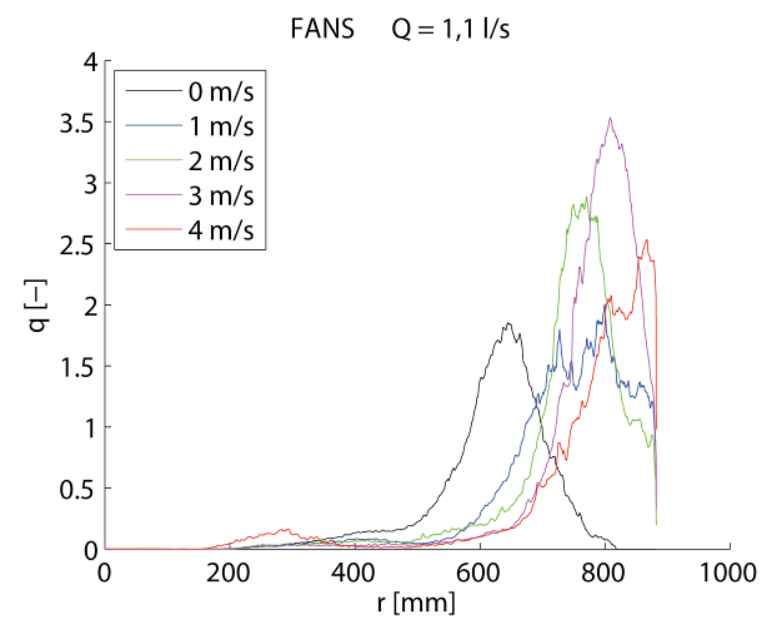

Figure 20. The water distribution of the nozzle FANS for several velocities of crossflow airstream and same water flow rate $1.1 \mathrm{l} / \mathrm{s}$.

\section{Conclusions}

The water distribution characteristic of spray nozzle with plate used in cooling towers is very important for the cooling tower design. We would like to have a uniform water load at the entry to the fill. We are able to set the uniform water load by choosing the distance between nozzles and pipelines. An in this case the water distribution characteristic plays an important role.

It provides qualitative evaluation of the uniform water load.

Water distribution characteristics can be predicted on the basis of experimental data of the spray nozzle with plate. Water distribution of a spray nozzle often include the maximum operate radius of the nozzle for one distance between a fill and a nozzle usually when we use measuring cylinders.

If we would like to obtain the maximum operate radium of a spray nozzle for several distances between a fill and a spray nozzle by one measurement we choosed the visualisation method. It this case we didn't obtain the exact water flow rate. But we obtained important information about how water is distributed below the spray nozzle. The measurement of water distribution characteristics of the nozzle is not sufficient just for the one airstream velocity. And for each airstream velocity it is needed to measure the water distribution characteristics by the visualisation method.

The visualisation method shows that the effect of counterflow is very strong if the water film near the spray plate occurs. The water film near the spray plate is very sensitive to air velocity change. In the same case it is able to create the water bell effect.

\section{Acknowledgments}

The author acknowledge the support received from Advanced technologies for heat and electricity production TE01020036 and Centre for research of multiphase flow and thermodynamics processes in renewable sources and 
energetics - NEW ENERGY supported by European Union (reg. n. CZ.2.16/3.1.00/22130).

\section{References}

1. Reuter, H.C.R., Viljoen, D.J., Kröger, D.G., IHTC 14, 4, pp. 619-628 (2010).

2. P. Vitkovic, V. Syrovatka, JFlowVisImageProc, 16 pp. 367-375 (2009).

3. Mark A. Linne, Megan Paciaroni, James R. Gord, and Terrence R. Meyer, Appl. Opt. 44, 6627-6634 (2005)

4. BALASUBRAMANYAM, M.S. a C.P. CHEN. IJHMT, 51, 3896-3905 (2008)

5. IM, K. -S., K. -C. LIN, M. -C. LAI a M. S. CHON, IJAT, 12, 489-496 (2011)

6. PAI, M. G., O. DESJARDINS a H. PITSCH. CTR (2008).

7. TAYlOR, G. a L. HOWARTH, Proc. R. Soc. A, 1274, s. 289-295 (1959) 